\title{
Determining Quality of Life and Associated Factors in Patients with Stroke
}

\author{
Serda EM ${ }^{1}$, Mehtap BOZKURT ${ }^{1}$, Mehmet KARAKOÇ ${ }^{1}$, Mehmet ÇAĞLAYAN ${ }^{1}$, Dicle AKDENIZ1 ${ }^{1}$, Pelin OKTAYOĞLU', Sefer VAROL², \\ Kemal NAS \\ 'Department of Physical Medicine and Rehabilitation, Dicle University Faculty of Medicine, Diyarbakır, Turkey \\ ${ }^{2}$ Department of Neurology, Dicle University Faculty of Medicine, Diyarbakır, Turkey
}

\begin{abstract}
Objective: This study aims to examine the overall and domain-specific quality of life in patients with stroke and to identify variables predicting quality of life after stroke.

Material and Methods: A total of 104 patients with sufficient cognitive functions having hemiplegia because of cerebrovascular accident and 108 controls were included in this study. Demographic and clinical features were recorded. The Barthel Index (BI) and Functional Ambulation Category scale were employed to assess the functional state of patients. Quality of life was evaluated by the Short Form 36 (SF-36) health survey, whereas the emotional state of the patients was evaluated by the Hospital Anxiety and Depression Scale (HADS). Functional status, motor impairment, and emotional state were determined as independent variables, and multiple regression analysis was used to predict quality of life.

Results: Patients had significantly lower scores in the quality of life subscores and total scores in comparison with the controls ( $p<0.001)$. The mean anxiety and depression rates in the patients were significantly higher than those in controls $(p<0.001)$. The sum of subscores and physical composite score of SF-36 were significantly lower in female and illiterate patients than in male and educated patients. Multiple regression analyses indicated that HADS depression was associated with mental health $(p<0.001)$, whereas BI was independently associated with the physical health total score $(p<0.05)$. The power of the statistical analysis for study population was $100 \%$ according to the given effect size $(\alpha=0.01)$.

Conclusion: Present results demonstrated that patients with stroke have a significantly poor quality of life than the general population. The reduced quality of life after stroke appears to be related the emotional state, physical disability, and demographic properties such as gender and education. Therefore, prevention of disability and early diagnosis and treatment of depression are vital in improving the quality of life of patients with stroke.
\end{abstract}

Keywords: Stroke, quality of life, anxiety, depression, disability

\section{Introduction}

Stroke is a disorder characterized by focal neurologic deficit (1). It has influences on the quality of life (QOL) of patients because of its associated physical and cognitive sequela, such as limitations in mobility and physical functioning, and depression $(2,3)$. Although it causes major significant functional sequela, objective assessment approaches often fail to evaluate the subjective impact of these impairments (4).
Health-related QOL (HRQOL) usually reflects the patients' subjective and personal evaluation of their own health status (5). Therefore, HRQOL refers to the difference between idealized functions and the functions that emerged because of the disease (6). Increasing HRQOL of patients has become the current medical target because it is the most important evaluation criteria before, during, and after the implementation of the rehabilitation program (7). Many studies have evaluated HRQOL

Address for Correspondence: Serda Em, MD, Dicle Üniversitesi Tıp Fakültesi, Fiziksel Tıp ve Rehabilitasyon Anabilim Dalı, Diyarbakır, Türkiye. Phone: +90 4122488030 E-mail: serdaem@hotmail.com

Received: April 2014 Accepted: August 2014

OCopyright 2015 by Turkish Society of Physical Medicine and Rehabilitation - Available online at www.ftrdergisi.com

Cite this article as: 
of patients with stroke and have also investigated the factors affecting HRQOL $(2,8-11)$. Some of them have reported disruption in HRQOL $(8-10,12)$, whereas others have not reported significant changes in $\operatorname{HRQOL}(2,13)$.

Emotional alterations are often observed after stroke $(14,15)$ that are generally associated with reduced QOL in stroke survivors (10,16-18). Earlier studies have also indicated that the functional status and depression are significant predictors of HRQOL $(3,19)$.

The previous studies largely consider limited factors to evaluate the relationship between $\mathrm{QOL}$ and stroke with controversial outcomes $(2,8-10,12,13)$. For example, there are a limited number of studies investigating the effect of emotional status, functional health, and demographic properties on the QOL of patients with stroke $(2,8-11)$. On the basis of previous reports of impairments in life quality of patients with stroke, we speculate that a variety of factors, such as sociodemographic, functional state, disability level, and emotional state, would have a significant influence on HRQOL of patients with stroke. This study aims to assess the QOL of patients with stroke and identify a relatively larger number of factors affecting the QOL of patients. This may provide a broader perspective in evaluating these patients and also guide to improve their QOL and rehabilitation process.

\section{Material and Methods}

\section{Study Group}

A total of 104 patients (60 males and 44 females) with hemiplegia who were either admitted to the Neurology and our outpatient clinic or stayed in our in-patient rehabilitation clinic between January 2014 and March 2014 and 108 healthy controls were included in this cross-sectional study. The patient group comprised patients with sufficient cognitive functions and physical disabilities who had a stroke for at least 4 weeks, and all patients have received rehabilitation in the same unit and at similar times. The control group was randomly selected from subjects with no physical or psychological disease-causing disability who are age and gender matched with patients. Exclusion criteria included extracerebral or subarachnoid hemorrhage or transient ischemic attack, brain tumor or other accompanying severe diseases, mental disease or loss of consciousness, language disorder, a lack of comprehension ability (motor-sensory aphasia), and with treatment for emotional disorder.

The individual rehabilitation physician managing the patient conducted the screening of patients for this study. Demographic information gathered from the patients included age, gender, educational state, income, and marital status. The patients were classified in terms of their incomes: those with income of $<1000$ TL salary per month were classified as low and those with income of $>1000$ TL salary per month were classified as high. Stroke time, laterization of stroke, and type of stroke, such as ischemic (thrombotic, embolic) and hemorrhagic (hypertensive intracerebral), were recorded.

The study was approved by the Ethics Committee of the Faculty, and it was conducted in accordance with the Declaration of Helsinki and the French Good Clinical Practices. Prior to the initiation of this study, the patients and controls provided their informed consent for the study in the written form after obtaining the required information regarding the study.

\section{Measurements}

The cognitive function of patients was assessed by the Mini Mental State Evaluation, disability level of patients was evaluated by the Barthel Index (BI), and their ambulatory capacity was evaluated by Functional Ambulation Category (FAC). Motor state was assessed in the upper and lower extremity using the Brunnstrom motor evaluation scale. Spasticity was evaluated using the Ashworth scale. The Short Form 36 Health Survey (SF36) was used to determine the QOL of patients and controls, whereas their emotional state was assessed by the Hospital Anxiety and Depression Scale (HADS).

\section{Mini Mental State Evaluation}

Mini Mental State Evaluation is a measurement that is frequently used to evaluate cognitive function and is a reliable and validated method $(20,21)$. It has a cut-off score of 24 for cognitive dysfunction (20).

\section{Barthel Index}

Barthel Index is used to measure the disability experienced by the patient in performing activities of daily living. The $\mathrm{BI}$ comprises 10 items regarding activities of daily living and mobility and assesses feeding, transfer from wheelchair to bed and back, self-care, bathing, walking, climbing stairs, dressing, and bladder and bowel continence. Scoring is based on whether the patient requires help or not in performing any of the above mentioned activities where scores between 21-61 mean severely dependent; between 62-90 mean moderately dependent; between $91-99$ mean mildly dependent; and 100 means completely independent (22). The Turkish validity and reliability of this scale was verified by Küçükdeveci et al. (23).

\section{Functional Ambulation Category}

The FAC is a scale that measures the ambulation ability of the patient. It comprises six categories ranging from 0 to 5 , where 0 means non-functional ambulation and 5 means independent ambulation (24).

\section{Brunnstrom Motor Evaluation Scale}

Brunnstrom scale is a measurement that is used to assess the recovery in motor functions. The lowest stage (flaccid stage and no voluntary movement) is stage $\mathrm{I}$, and the highest stage (isolated joint movement) is stage VI. Validity and reliability have been previously demonstrated (25).

\section{Ashworth Scale}

Spasticity was measured using the following 5-point Ashworth scale: 0 is no increase in muscle tone; 1 is slight increase in muscle tone that is demonstrated by a catch at the end range of motion (ROM); 2 is the noticeable increase in muscle tone through most ROM, such that the affected limb is easily movable; 3 is the considerable increase in muscle tone but difficult passive movement of the affected limb; and 4 is the rigid affected limb (26). 


\section{Short Form-36 Health Survey}

The SF-36 is a generic, subjective measure of HRQOL. It allows assessment across eight health domains: physical functioning (PF), role limitations due to physical problems (RP), bodily pain (BP), general health $(\mathrm{GH})$, vitality $(\mathrm{VT})$, social functioning $(\mathrm{SF})$, role limitations due to emotional problems (RE), and mental health $(\mathrm{MH})$. The scores of these eight domains can also be summated in two major categories: physical composite score (PCS) and mental composite score (MCS) to reflect the overall physical and mental health, respectively. Scores of 100 for PF, RP,

Table 1. Sociodemographic characteristic of patients and controls

\begin{tabular}{|c|c|c|c|}
\hline & $\begin{array}{l}\text { Patients } \\
\mathrm{n}=104\end{array}$ & $\begin{array}{l}\text { Controls } \\
n=108\end{array}$ & $\mathbf{p}$ \\
\hline Mean age $\pm S D$ (year) & $57.40 \pm 12.50$ & $56.03 \pm 10.81$ & 0.87 \\
\hline Gender, n (\%) & & & 0.24 \\
\hline Male & $60(57.7)$ & $50(46.3)$ & \\
\hline Female & $44(42.3)$ & $48(53.7)$ & \\
\hline Marital status, n (\%) & & & 0.67 \\
\hline Married & $98(94.2)$ & $96(88.9)$ & \\
\hline Single & $6(5.8)$ & $12(11.1)$ & \\
\hline Education year, n (\%) & & & 0.973 \\
\hline Illiterate & $68(65.4)$ & $71(65.7)$ & \\
\hline Primary school & $20(19.2)$ & $22(20.4)$ & \\
\hline High school & $12(11.5)$ & $12(11.1)$ & \\
\hline University & $4(3.9)$ & $3(2.8)$ & \\
\hline Income status n (\%) & & & 0.75 \\
\hline Higher income & $22(21.1)$ & $36(33.3)$ & \\
\hline Lower income & $82(78.9)$ & $72(66.7)$ & \\
\hline
\end{tabular}

SD: standard deviation

Table 2. Characteristics of patients related to hemiplegia

\begin{tabular}{lc} 
Characteristics & \\
\hline Disease duration (month) & $16.86 \pm 12.23$ \\
Mean \pm SD & \\
Nature of lesion $\mathrm{n}(\%)$ & $76(73)$ \\
Infarct & $28(27)$ \\
Hemorrhage & \\
Side of lesion (\%) & $60(57.7)$ \\
Right & $40(38.5)$ \\
Left & $4(3.5)$ \\
Bilateral & $50.96 \pm 27.31$ \\
Barthel Index Score mean $\pm S D$ & 1.00 \\
FAC median & 0.00 \\
Min & 5.00 \\
Max &
\end{tabular}

FAC: Functional Ambulation Category; SD: standard deviation
$\mathrm{BP}, \mathrm{SF}$, and RE domains and scores of 50 in the remaining three domains, $\mathrm{GH}, \mathrm{VT}$, and $\mathrm{MH}$, indicate an absence of problems in those areas. For example, a score of 100 in physical functioning indicates an ability to perform all activities without limitations due to health; a score of 50 in mental health indicates an ability to function without personal or emotional problems. To obtain scores. The score of 50 for $\mathrm{GH}, \mathrm{VT}$, and $\mathrm{MH}$, health must be positively evaluated. For example, a score of 100 in the mental health domain indicates that the respondent feels peaceful and happy and is calm all the time. The Turkish version of this scale was verified in terms of its validity and reliability by Koçyiğit et al. (27). The SF-36 has been validated for use among people with stroke and is considered suitable through a face-to-face interview (13).

\section{Hospital Anxiety and Depression Scale}

The HADS is a simple and reliable test that is used in medical practice. Its Turkish version has been demonstrated to be valid and reliable (28). It comprises 14 questions, half of which constitutes the anxiety subscale, whereas the other half constitutes the depression subscale. Response options include "not at all," "occasionally," "quite often," and "very often," which is scored from 0 to 3 . Items of the depression and anxiety subscales are scored between 0-21, where $0-7$ indicates normal, 8-10 indicates mild, 11-14 indicates moderate, and 15-21 indicates severe mood disorders (29).

\section{Statistical Analysis}

The calculations were performed using the Statistical Package for Social Sciences software version 16.0 (IBM SPSS Inc., Chicago, IL, USA) for Windows. Measurement variables were expressed in mean \pm standard deviation, whereas categorical

Table 3. Quality of life and emotional state of patients with stroke and the controls

\begin{tabular}{lccc}
\hline & $\begin{array}{c}\text { Patients } \\
\mathbf{n}=\mathbf{1 0 4}\end{array}$ & $\begin{array}{c}\text { Controls } \\
\mathbf{n}=\mathbf{1 0 8}\end{array}$ & $\mathbf{p}$ \\
\hline PF & $11.07 \pm 16.86$ & $80.31 \pm 18.21$ & $<0.001$ \\
RP & $10.92 \pm 8.35$ & $76.06 \pm 32.53$ & $<0.001$ \\
BP & $41.63 \pm 25.08$ & $65.97 \pm 25.49$ & $<0.001$ \\
GH & $25.69 \pm 15.94$ & $58.95 \pm 22.16$ & $<0.001$ \\
VT & $31.73 \pm 20.24$ & $59.25 \pm 20.87$ & $<0.001$ \\
SF & $30.52 \pm 20.02$ & $74.46 \pm 18.04$ & $<0.001$ \\
RE & $21.45 \pm 21.21$ & $70.21 \pm 40.67$ & $<0.001$ \\
MH & $41.46 \pm 19.41$ & $65.53 \pm 21.83$ & $<0.001$ \\
PCS & $25.00 \pm 5.74$ & $47.45 \pm 8.61$ & $<0.001$ \\
MCS & $35.58 \pm 7.57$ & $45.80 \pm 10.51$ & $<0.001$ \\
HADS & & & \\
\multicolumn{1}{c}{ Anxiety } & $11.11 \pm 5.41$ & $6.00 \pm 3.72$ & $<0.001$ \\
Depression & $11.19 \pm 5.16$ & $6.82 \pm 4.26$ & $<0.001$ \\
\hline
\end{tabular}

PF: Physical Functioning; RP: role limitations because of physical problems; BP: bodily pain; GH: general health; VT: vitality; SF: social functioning; RE: role limitations because of emotional problems; MH: mental health; PCS: Physical Component Summary; MCS: Mental Component Summary; HADS: Hospital Anxiety and Depression Scale. $\mathrm{P}<0.05$ is statistically significant 


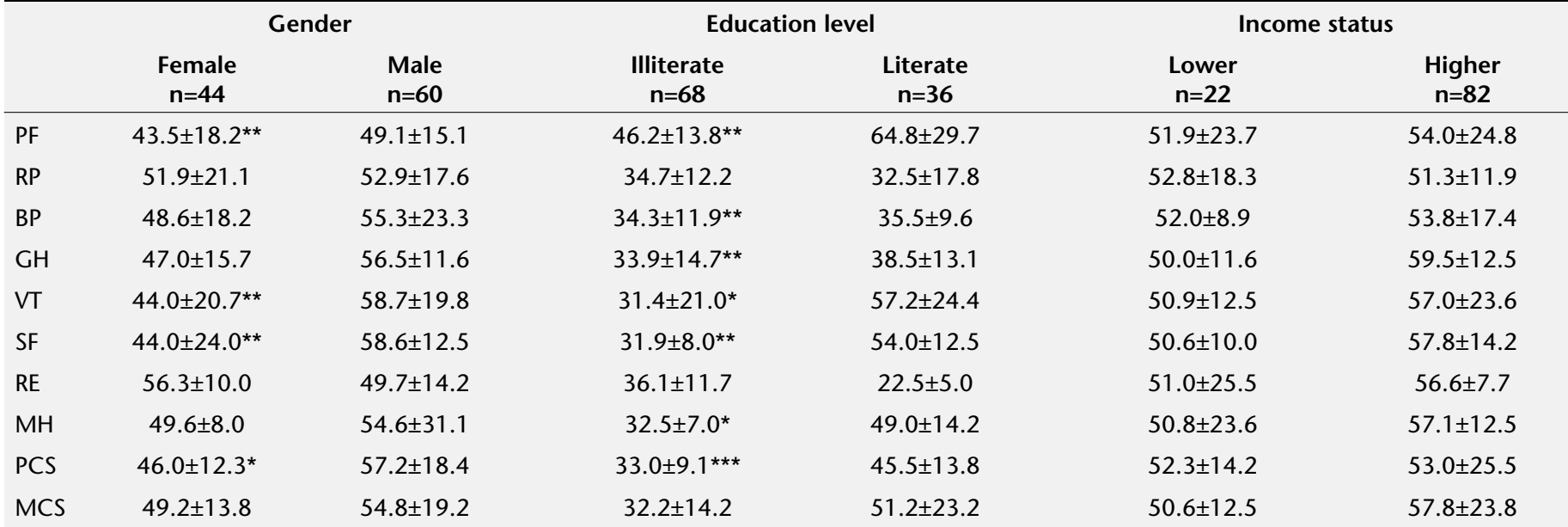

PF: Physical Functioning; RP: role limitations because of physical problems; BP: bodily pain; GH: general health; VT: vitality; SF: social functioning; RE: role limitations because of emotional problems; MH: mental health; PCS: Physical Component Summary; MCS: Mental Component Summary; HADS: Hospital Anxiety and Depression Scale, ${ }^{* * *} p<0.001,{ }^{* *} p<0.01,{ }^{*} p<0.05$

Table 5. Correlation between the SF-36 domains with age, emotional state, functional state and clinical parameters in patients with stroke

\begin{tabular}{|c|c|c|c|c|c|c|c|c|c|c|}
\hline & Age & $\begin{array}{c}\text { Stroke } \\
\text { duration }\end{array}$ & HADS-A & HADS-D & Barthel & $\begin{array}{l}\text { FAC } \\
\text { upper }\end{array}$ & $\begin{array}{l}\text { Brunnstrom } \\
\text { lower }\end{array}$ & $\begin{array}{l}\text { Brunnstrom } \\
\text { upper }\end{array}$ & $\begin{array}{l}\text { Ashworth } \\
\text { lower }\end{array}$ & Ashworth \\
\hline PF & -.007 & -.050 & $-.499^{* *}$ & $-.535^{\star *}$ & $.692^{\star *}$ & $.717^{\star *}$ & $.384^{* *}$ & $.630^{* *}$ & -.119 & $-.364^{\star *}$ \\
\hline RP & .012 & .085 & $-.502^{\star \star}$ & $-.488^{\star \star}$ & -.005 & .059 & .033 & .137 & .104 & -.028 \\
\hline $\mathrm{BP}$ & .014 & .188 & $-.496^{\star *}$ & $-.575^{\star *}$ & $.456^{\star *}$ & $.402^{\star *}$ & $.212^{*}$ & $344^{* *}$ & .123 & .005 \\
\hline $\mathrm{GH}$ & -.051 & .097 & $-.671^{\star *}$ & $-.639^{\star \star}$ & $.446^{\star *}$ & $.344^{\star}$ & $.356^{\star *}$ & $275^{* *}$ & -.001 & .091 \\
\hline VT & -.107 & .082 & $-.663^{* *}$ & $-.680^{\star \star}$ & $.454^{\star \star}$ & $.420^{\star \star}$ & $.244^{*}$ & $.346^{* *}$ & -.011 & -.02 \\
\hline RE & -.109 & .075 & $-.330^{\star *}$ & $-.398^{\star \star}$ & $-.305^{*}$ & -.159 & .084 & $.207^{\star}$ & .057 & .085 \\
\hline $\mathrm{MH}$ & .001 & .062 & $-.687^{\star *}$ & $-.727^{\star \star}$ & $.472^{\star \star}$ & $.341^{\star}$ & $.325^{\star \star}$ & $.317^{\star \star}$ & -.066 & .007 \\
\hline PCS & .005 & .012 & $-.517^{\star \star}$ & $-.528^{\star \star}$ & $.612^{\star \star}$ & $.602^{\star \star}$ & $.253^{\star *}$ & $.591^{\star *}$ & .009 & -.152 \\
\hline MCS & -.058 & .219 & $-.635^{\star *}$ & $-.693^{\star *}$ & $.366^{\star *}$ & $.314^{\star}$ & $.292^{\star *}$ & $.285^{\star *}$ & -.089 & .034 \\
\hline
\end{tabular}

PF: Physical Functioning; RP: role limitations because of physical problems; BP: bodily pain; GH: general health; VT: vitality; SF: social functioning; RE: role limitations because of emotional problems; MH: mental health; PCS: Physical Component Summary; MCS: Mental Component Summary; FAC: Functional Ambulation Category; HADS: Hospital Anxiety and Depression Scale. $<0.05$ is statistically significant. ${ }^{*}$ Correlation is significant at the $p<0.05$, ${ }^{* *}$ correlation is significant at the $p<0.01,{ }^{* \star *}$ correlation is significant at the $p<0.001$

variables were presented in numbers and percentages (\%). Kolmogorow-Smirnow test was used to analyze the compliance of datasets with the normal distribution. Student's t-test was used to compare the mean values of the group that displayed a normal distribution, and Mann-Whitney $U$ test was used for the group that did not display a normal distribution. Varying frequencies among the categorical groups were evaluated by Chi-square test. Spearman's correlation test was for correlation analysis. Multiple regression analysis was used to predict the QOL. A enter method was used to construct the multiple regression analyze with respect to various dependent variables. Statistical significance was based on a value of $\mathrm{p}<0.05$ with a 95\% confidence interval.

\section{Results}

Sociodemographic characteristics of patients and controls are presented in Table 1. The mean age of patients with stroke was found to be $57.40 \pm 12.50,57.7 \%$ patients were male, $94.2 \%$ were married, $65.4 \%$ were illiterate, and $78.9 \%$ had a low income. A significant difference was not found between the patients and controls in terms of age, gender, marital status, education, and income. The patients' clinical features are demonstrated in Table 2, and the patients' QOL and emotional state-related data are demonstrated in Table 3 . The mean stroke time was found as $16.86 \pm 12.23$ month ( $\min =3$ month, $\max =60$ month). Infarct was the major type of stroke (73\%).

The patients had disabilities with a mean BI score of 50.96 \pm 27.3 . Total scores and sub-scores of SF-36 were sig- 
Table 6. Multiple linear regression analyses in patients with stroke

\begin{tabular}{lccccccc} 
& \multicolumn{3}{c}{ MCS } & & \multicolumn{3}{c}{ PCS } \\
\cline { 2 - 4 } \cline { 7 - 8 } Variables & $\mathbf{B}$ & $\mathbf{t}$ & $\mathbf{p}$ & & $\mathbf{B}$ & $\mathbf{t}$ & $\mathbf{p}$ \\
\hline HADS anxiety & -.392 & -1.853 & .067 & & .030 & .351 & .194 \\
HADS depression & -.643 & -8.48 & $<0.001$ & & -.113 & -1.307 & .194 \\
Barthel & .105 & 1.299 & .197 & & .577 & 7.141 & $<0.001$ \\
FAC & .099 & 1.260 & .210 & $.173 a$ & 1.124 & .264 \\
\hline
\end{tabular}

MCS: Mental Component Summary; PCS: Physical Component Summary; HADS: Hospital Anxiety and Depression Scale; FAC: Functional Ambulation Category. MCS, PCS as dependent variable, HADS anxiety, HADS depression, Barthel and FAC as independent variables. $p<0.001$ statistically significant

nificantly lower $(p<0.001)$ in patients. Patients with stroke had significantly higher levels of anxiety and depression than the control subjects. The relationship between demographic and clinical characteristics of patients and the SF-36 domains are demonstrated in Table 4. Patients were separated in two groups for stroke duration as acute-subacute ( $<6$ months) and chronic stroke ( $>6$ months). Furthermore, they were classified in terms of their incomes. It was found that there was no significant difference in the QOL in these groups (Table 4). Some sub- and total scores of SF-36 were significantly different in patients who were grouped with regard to their gender and education. A significant negative correlation was found between SF-36 sub- and total scores and emotional state scores, whereas a significant positive correlation was found between SF-36 sub- and total scores and $\mathrm{BI}$ scores (Table 5). The Brunnstrom scores of the lower and upper extremity and FAC were significantly correlated with PCS and MCS total scores of the SF-36 health survey. The multiple regression analyses indicated that $\mathrm{BI}$ was independently associated with PCS total score $\left(R^{2}=0.33 ; p<0.001\right)$ and HADS depression score associated with $\mathrm{MCS}\left(\mathrm{R}^{2}=0.414 ; \mathrm{p}<0.001\right)$ (Table 6).

\section{Discussion}

In stroke rehabilitation, accurately constructed, valid, and reliable measures are required to categorize patients, to predict future conditions, and to evaluate patient outcomes or the effectiveness of interventions (30). The present study underlines the general health status of the patients with stroke. Furthermore, the study examines the emotional state of patients and identifies the factors affecting the QOL.

The HRQOL is a recognized and important outcome after stroke (19), and it is the most important evaluation criteria during the implementation of the rehabilitation program (31). Therefore, information gained from HRQOL are useful in recognizing the patients' problems, determining treatment priorities, managing interventions, monitoring disease period, and for health economics, and identifying new ideas and solutions to the revealed problems (7).

The present study demonstrates that all the parameters of the SF-36 scores of the patients have a significantly higher level of disruption compared with those of controls. These results are consistent with the results of previous studies $(7,12,13,25,32$ -
35), although they include a heterogeneous population and employ HRQOL with a wider variety of scales, including studies conducted on Turkish population. In contrast, a study reports a slight change in HRQOL of patients with stroke (8). This study has a rather older patient population (72 \pm 12$)$ and half of them had a stroke history before. Therefore, this slight change may be associated with the fact that these patients have already limited social activities before stroke.

The other objective of this study was to observe whether there exists a relationship between HRQOL and the emotional state, physical state, and demographic characteristics of patients. Earlier studies have also indicated that the most significant predictors of HRQOL are functional status and depression $(3,4,10,16-19,25,36)$, although a study demonstrated a more generalized adverse effect on HRQOL than functional disabilities (37), and some who have demonstrated disability alone explained little regarding the variance in the $\mathrm{QOL}(2,38)$. The results produced from the current study demonstrated that the anxiety and depression scores in patients were significantly higher compared with those in controls. The major finding of the present study is that the depressive moods of patients are independently associated with MCS in the multiple regression analysis. Moreover, disability as independent variables was found to affect the physical health of patients. The Barthel score was positively correlated with PCS and MCS, whereas HADS anxiety and depression were negatively correlated with these variables. Hence, this may suggest that patients should be more closely monitored, and they should be provided with psychological support.

There are studies indicating the association of motor recovery and the QOL $(7,10)$. Ones et al. (7) revealed that upper extremity Brunnstrom scores of the patients were positively correlated with the Nottingham Health Profile scores, whereas lower extremity Brunnstrom scores were not correlated with the Nottingham Health Profile scores. Nevertheless, we have found that the lower extremity and ambulation function are associated with the QOL as much as the upper extremity. Moreover, this study demonstrated that patients with severe disability had lower SF-36 scores and higher HADS scores compared with patients with mild-moderate disability. The difference in the population and diversity in methodologies employed in Ones et al. (7) study may be the cause of the controversial results.

The results of this study indicated that there was no significant relationship between the level of spasticity and HRQOL that may suggest that the presence or the absence of spasticity has no important contribution to the functional improvement. Ones et al. (7) revealed that there was no significant relationship between spasticity level and QOL.

In this study, $57 \%$ of 104 patients were males, $65.4 \%$ illiterate, and $78.9 \%$ had low income. Some studies report different association between the level of education, age, gender, and HRQOL. There are a number of studies that demonstrate that female patients with stroke have lower HRQOL compared with males $(10,25,39)$, although a study has reported no significant differences (33). Kranciukaite et al. (33) demonstrated that HRQOL is correlated with education and employment. Further- 
more, Gokkaya et al. (25) indicated that HRQOL is associated with the income of patients with stroke. In contrast, Carod-Artal et al. (10) reported that HRQOL is not poorly correlated with these parameters. In the current study, there was a significant difference between female and male patients with stroke in terms of HRQOL, and illiterate patients had significantly lower physical health total scores and some subscores (PF, BP, GH,VT, $\mathrm{SF}$, and $\mathrm{MH}$ ) compared with literate patients. The social, cultural, and regional diversities in the patient population employed in different studies may be the cause of the controversial results in the literature. Females are more heavily involved in housekeeping compared with males in our region; thus, this may influence the physical health of females. The results demonstrated that gender and educational level may have a considerable influence on HRQOL, whereas it is not influenced by income. According to these results, we suggest that female patients and patients with lower income should be considered in a well-designed rehabilitation protocol to enhance their QOL.

Our findings demonstrated that there was no association between HRQOL and age as previously reported $(7,10,25)$; although some studies demonstrated a negative association between HRQOL and age $(11,32,40)$, another study demonstrated a positive correlation (2). These controversial results may be ascribed to the different methodologies employed in each study.

There are a few limitations in this study that should be mentioned. The study group is relatively small for more objective outcomes, and it does not cover all the categories of the society. The other limitation of this study is the lack of patients' emotional state and QOL at the beginning of the study.

\section{Conclusion}

Results of this study indicated that patients with stroke have a significantly poor QOL than the general population. The reduced QOL after stroke appears to be related not only to the emotional state and physical disability but also to some demographic properties, such as gender and education. Because the disability level and depressive mood after the stroke are important factors in the prediction of physical and mental healths of patients, the prevention of disability and early diagnosis and treatment of depression is vital in the improvement of HRQOL of patients with stroke.

Ethics Committee Approval: Ethics committee approval was received for this study from the ethics committee of Dicle University Faculty of Medicine.

Informed Consent: Written informed consent was obtained from patients who participated in this study.

Peer-review: Externally peer-reviewed.

Author Contributions: Concept - S.E.; Design - S.E., M.B.; Supervision - S.E., M.K., K.N.; Resource - S.E., P.O.; Materials - S.E., M.C., M.K.; Data Collection and/or Processing - S.E., D.A., S.V.; Analysis and/or Interpretation - S.E., M.B.; Literature Review - S.E., M.B.; Writer - S.E.; Critical Review - K.N.

Conflict of Interest: No conflict of interest was declared by the authors.
Financial Disclosure: The authors declared that this study has received no financial support.

\section{References}

1. Garrison SJ, Rolak LA. Rehabilitation of the stroke patient. In: DeLisa JA, ed. Rehabilitation medicine: Principles and practice. 2nd edition. Philadelphia: JB Lippincott Co, 1993. p.801-24.

2. King RB. Quality of life after stroke. Stroke 1996;27:1467-72. [CrossRef]

3. Kim $\mathrm{P}$, Warren $\mathrm{S}$, Madill $\mathrm{H}$, Hadley M. Quality of life of stroke survivors. Qual Life Res 1999;8:293-301. [CrossRef]

4. Laurent K, De Sèze MP, Delleci C, Koleck M, Dehail P, Orgogozo JM, et al. Assessment of quality of life in stroke patients with hemiplegia. Ann Phys Rehabil Med 2011:54;376-90. [CrossRef]

5. Ware JE Jr. Conceptualization and measurement of health-related quality of life: Comments on an evolving field. Arch Phys Med Rehabil 2003;84:43-51. [CrossRef]

6. van Straten A, de Haan RJ, Limburg M, van den Bos GA. Clinical meaning of the Stroke-Adapted Sickness Impact Profile-30 and the Sickness Impact Profile-136. Stroke 2000;31:2610-5. [CrossRef]

7. Ones K, Yilmaz E, Cetinkaya B, Caglar N. Quality of life for patients poststroke and the factors affecting it. I Stroke Cerebrovasc Dis 2005;14:261-6. [CrossRef]

8. Muro MJ, de Pedro-Cuesta J, Almazán J, Holmqvist LW. Stroke patients in south Madrid: function and motor recovery, resource utilization, and family support. Stroke 2000;31:1352-9. [CrossRef]

9. Hochstenbach JB, Anderson PG, van Limbeek J, Mulder TT. Is there a relation between neuropsychologic variables and quality of life after stroke? Arch Phys Med Rehabil 2001;82:1360-6. [CrossRef]

10. Carod-Artal J, Egido JA, Gonzalez J, Varela de Seijas E. Quality of life among stroke survivors evaluated 1 year after stroke.Stroke 2000;31:2995-3000. [CrossRef]

11. Niemi ML, Laaksonen R, Kotila M, Waltimo O. Quality of life 4 years after stroke. Stroke 1988;19:1101-7. [CrossRef]

12. Mayo NE, Wood-Dauphinee S, Côté R, Durcan L, Carlton J. Activity, participation, and quality of life 6 months poststroke. Arch Phys Med Rehabil 2002;83:1035-42. [CrossRef]

13. Hackett ML, Duncan JR, Anderson CS, Broad JB, Bonita R. Health related quality of life among long-term survivors of stroke: Results from the Auckland stroke study, 1991-1992. Stroke 2000;31:440-7. [CrossRef]

14. Murtezani A, Hundozi H, Gashi S, Osmani T, Krasniqi V, Rama B. Factors associated with reintegration to normal living after stroke. Med Arh 2009;63:216-9.

15. Hackett ML, Anderson CS, House AO, Xia J. Interventions for treating depression after stroke. Cochrane Database Syst Rev 2008;8:CD003437. [CrossRef]

16. Clarke PJ, Lawrence JM, Black SE. Changes in quality of life over the first year after stroke: findings from the Sunnybrook Stroke Study. I Stroke Cerebrovasc Dis 2000;9:121-7. [CrossRef]

17. Kauhanen ML, Korpelainen JT, Hiltunen P, Nieminen P, Sotaniemi KA, Myllylä VV. Domains and determinants of quality of life after stroke caused by brain infarction. Arch Phys Med Rehabil 2000;81:15416. [CrossRef]

18. Suenkeler IH, Nowak M, Misselwitz B, Kugler C, Schreiber W, Oertel $\mathrm{WH}$, et al. Time course of health-related quality of life as determined 3, 6 and 12 months after stroke. Relationship to neurological deficit, disability and depression. J Neurol 2002;249:1160-7. [CrossRef]

19. Carod-Artal FJ, Egido JA. Quality of life after stroke: the importance of a good recovery. Cerebrovasc Dis 2009;27:204-14. [CrossRef] 
20. Folstein MF, Folstein SE, McHugh PR. Mini-mental state: A practical method for grading the cognitive state of patients for the clinician. J Psychiatr Res 1975;12:189-98. [CrossRef]

21. Foreman MD. Reliability and validity of mental status questionnaires in elderly hospitalized patients. Nurs Res 1987;36:216-20. [CrossRef]

22. Wade DT, Collin C. The Barthel ADL Index: a standard measure of physical disability? Disabil Rehabil 1988;10:64-7. [CrossRef]

23. Küçükdeveci AA, Yavuzer G, Tennant A, Süldür N, Sonel B, Arasıl T. Adaptation of modified Barthel Index for use in physical medicine and rehabilitation in Turkey. Scand J Rehabil Med 2000;32:87-92. [CrossRef]

24. Holden MK, Gill KM, Magliozzi MR, Nathan J, Piehl-Baker L. Clinical gait assessment inneurolgically impaired. Phys Ther 1984;64:3540.

25. Gokkaya NK, Aras MD, Cakci A. Health-related quality of life of Turkish stroke survivors. Int J Rehabil Res 2005;283:229-35. [CrossRef]

26. Brashear A, Zafonte R, Corcoran M, Galvez-Jimenez N, Gracies JM, Gordon MF, et al. Inter- and intrarater reliability of the Ashworth Scale and the Disability Assessment Scale in patients with upperlimb poststroke spasticity. Arch Phys Med Rehabil 2002;83: 134954. [CrossRef]

27. Koçyiğit H, Aydemir Ö, Ölmez N, Memis A. The validity and reliability of Turkish version of the short form 36 (SF-36) Turkish. J Drugs Therap 1999;112:102-6.

28. Aydemir O, Guvenir T, Kuey L, Kultur S. Hastane anksiyete ve depresyon olceği Turkce formunun gecerlilik ve guvenilirliği. Türk Psikiyatri Dergisi 1997;8:280-7.

29. McCullagh E, Brigstocke G, Donaldson N, Kalra L. Determinants of caregiving burden and quality of life in caregivers of stroke patients. Stroke 2005;36:2181-6. [CrossRef]
30. Nas K, Gür A, Cevik R, Saraç AJ. The relationship between physical impairment and disability during stroke rehabilitation: effect of cognitive status. Int J Rehabil Res 2004;27:181-4. [CrossRef]

31. Greenberg JP, Good DJ. Functional assessment in neurologic disability. In: Lazar RB, ed. Principles of neurologic rehabilitation. New York: McGraw Hill, 1998. p.7-27.

32. Gallien P, Adrien S, Petrilli S, Durufle A, Robineau S, Kerdoncuff V, et al. Home care and quality of life three years after stroke. Ann Readaptation Med Phys 2005;48:225-30. [CrossRef]

33. Kranciukaite D, Rastenyte D, Jureniene K, Sopagiene D. Quality of life in stroke survivors. Medicina (Kaunas) 2007;43:736-45.

34. Sturm JW, Donnan GA, Dewey HM, Macdonell RA, Gilligan AK, Srikanth V, et al. Quality of life after stroke: The North East Melbourne Stroke Incidence Study (NEMESIS). Stroke 2004;35:2340-5. [CrossRef]

35. Clark P, Marshall V, Black SE, Colantonio A. Well-being after stroke in Canadian seniors: findings from the Canadian Study of Health and Aging. Stroke 2002;33:1016-21. [CrossRef]

36. Jönsson AC, Lindgren I, Hallström B, Norrving B, Lindgren A. Determinants of quality of life in stroke survivors and their informal caregivers. Stroke 2005;36:803-8. [CrossRef]

37. Kwok T, Lo RS, Wong E, Wai-Kwong T, Mok V, Kai-Sing W. Quality of life of stroke survivors: a 1-year follow-up study. Arch Phys Med Rehabil 2006;87:1177-82. [CrossRef]

38. Viitanen M, Fugl-Meyer KS, Bernspång B, Fugl-Meyer AR. Life satisfaction in long-term survivors after stroke. Scand J Rehabil Med 1988;20:17-24.

39. Hopman WM, Verner J. Quality of life during and after inpatient stroke rehabilitation. Stroke 2003;34:801-5. [CrossRef]

40. de Haan RJ, Limburg M, Van der Muelen JH, Jacobs HM, Aaronson NK. Quality of life after stroke: Impact of stroke type and lesion location. Stroke 1995;26:402-8.[CrossRef] 